\title{
Poder judiciário e controle de políticas públicas de efetivação de direitos humanos
}

\author{
The judicial review of public policies regarding the accomplishment of human rights
}

Emílio Borges e Silva ${ }^{1}$

\section{Resumo}

\begin{abstract}
Visa o presente estudo abordar a possibilidade de intervenção do Poder Judiciário em matéria de políticas públicas desenvolvidas pelo Estado, por meio dos Poderes Executivo e Legislativo, como mecanismo de controle e efetivação dos direitos humanos. Expõe a discussão travada entre juristas que argumentam a impossibilidade de controle judicial, por violar, em tese, o princípio da separação dos poderes e a intangibilidade do mérito do ato administrativo discrionário, além de analisar de que forma deve ser interpretada a denominada reserva do possível quando o assunto é a implementação de políticas públicas relacionadas a direitos humanos. Demonstra que, no modelo do Estado Democrático e Social de Direito consagrado pela Constituição Federal de 1988, todas as formas de expressão do poder estatal encontram-se vinculadas à ideia de máxima efetividade dos direitos humanos, de modo que o Judiciário não deve quedar-se inerte em casos de omissão dos demais poderes em sua concretização.
\end{abstract}

Palavras-chave: Direitos Humanos. Políticas Públicas. Poder Judiciário. Controle.

\begin{abstract}
This study aims to address the possibility of intervention of the judiciary in matters of public policies developed by the State, through the executive and legislative branches, as a mechanism of control and enforcement of human rights. Exposes the discussion going on between lawyers who argue the impossibility of judicial review, for violating, in theory, the principle of Separation of Powers and the inviolability of the merits of the administrative dictionary act. Analyzes how the reserve of possibility should be interpreted on the issue of the implementation of public policies related to human rights. Demonstrates that, in the the model of the Democratic and Social State of Law enshrined by the Constitution of 1988, all forms of expression of state power are linked to the idea of maximum effectiveness of human rights, so that the judiciary should not be inert in cases of omission of the other branches on its implementation.
\end{abstract}

Keywords: Human Rights. Public Policies. Judiciary. Control.

Advogado graduado pela Universidade Estadual de Londrina; Pesquisador do programa de iniciação científica pela mesma universidade; Aluno especial da disciplina "Processos de Integração do Estado Contemporâneo" do curso de Mestrado em Direito Negocial da Universidade Estadual de Londrina. 


\section{Introdução}

O presente trabalho abordará as discussões atinentes à possibilidade de intervenção do Poder Judiciário em um campo de atuação tradicionalmente afeto aos poderes Legislativo e Executivo: a formulação e implementação de políticas públicas para a promoção e efetivação de direitos fundamentais.

O problema central consiste em definir em que medida este controle pelo Estadojuiz será compatível com o modelo de democracia e tripartição de poderes adotado pelo Brasil, haja vista que a formulação e execução de políticas públicas dependem, inicialmente, de opções políticas discricionárias dos membros dos poderes Executivo e Legislativo, os quais receberam, por delegação popular, as atribuições de adoção de medidas tendentes a satisfação das necessidades da sociedade que os elegeu como representantes.

Neste sentido, argumenta-se que haveria insanável déficit democrático na atuação dos juízes em matéria de controle de políticas públicas, pois representaria uma ilegítima invasão de poder reservado a outra função estatal.

Com efeito, eventual intervenção judicial poderia suscitar campos de tensão em relação aos demais poderes originariamente dotados da competência para delimitação e execução de políticas públicas, ocasionando uma aparente violação da clausula pétrea da separação dos poderes.

Outro argumento tradicionalmente utilizado para negar a possibilidade de ingerência jurisdicional em matéria de políticas públicas relacionadas a direitos fundamentais é a denominada reserva do possível, que traduz a necessidade de prévia dotação orçamentária como limite ao cumprimento imediato de decisão judicial em matéria relativa a políticas públicas.

Com o propósito de discorrer acerca deste aparente conflito de ideias, será analisada a temática da separação dos poderes dentro do modelo de Estado Democrático de Direito consagrado pela Constituição Federal brasileira de 1988.

O objetivo é reavaliar as funções do Poder Judiciário após a transição do Estado liberal para o Estado social no Brasil, partindo da premissa de que todos os poderes, inclusive o Judiciário, estão vinculados à consecução dos fins sociais, especialmente no que 
concerne à efetivação dos direitos fundamentais, a teor do que se extrai da interpretação do artigo 2으, à luz dos artigos 3ำ e 5ㅇ, XXXV, todos da Constituição Federal.

Desta forma, busca-se fundamentar que eventual omissão dos Poderes Legislativo e Executivo na satisfação espontânea de direitos fundamentais, inadimplindo obrigação constitucional e lesando direitos fundamentais, autoriza a tentativa de reparação por meio da provocação da tutela jurisdicional.

\section{Poder judiciário e efetivação dos direitos fundamentais no modelo de Estado}

\section{Democrático e Social de Direito}

A abordagem inicial do tema não poderia escapar de uma delineação do paradigma de Estado adotado pelo texto constitucional pátrio, para que, posteriormente, venha a ser contextualizado com a ideia de atuação do Poder Judiciário no controle de políticas públicas ligadas a direitos fundamentais.

A Constituição Federal de 1988 veio a estruturar um modelo de Estado Democrático de Direito com o intuito de enfrentar os problemas sociais, concedendo-lhes melhores soluções que outros estágios de evolução do Estado e do constitucionalismo.

Uma análise sistemática do texto constitucional faz ver que um grande número de dispositivos perfilha-se ao chamado Estado de bem-estar social:

\footnotetext{
Segundo essa ótica, a Constituição identificou como objetivos fundamentais da República, dentre outros, a construção de uma sociedade justa, a erradicação da pobreza e a redução das desigualdades sociais. Tais objetivos foram incorporados, ainda uma vez, pelas regras constitucionais da economia (art. 170 e s.), que, por disposição textual, ficou jungida a valorização social do trabalho e a realização da justiça social. Além disso, a educação e a saúde deixaram de ser tratadas como programas de caráter indicativo, para integrar o rol de Direitos Fundamentais do cidadão (ARAUJO, 2005, p. 93).
}

Neste contexto, a base política do modelo estatal brasileiro lastreia-se no respeito e promoção dos direitos fundamentais, notadamente os sociais, de maneira que todas as esferas de poder, Executivo, Legislativo e Judiciário, possuem o compromisso com a concretização destes direitos: 
O Estado Democrático de Direito se assenta na supremacia da Constituição, na democracia, na valorização do jurídico, na proteção aos direitos fundamentais e na aplicação imediata das normas constitucionais. Governantes e governados se submetem ao direito posto, com o propósito de garantir as liberdades fundamentais. O Direito se abre para o povo, que é chamado para dizer o que é justo para si e, assim, reformular o ordenamento. Dessa forma, a ideia de justiça é pensada constantemente (DRUMMOND, 2012).

Como expressões deste paradigma de Estado, a Constituição Federal de 1988 consagrou como um dos fundamentos da República Federativa do Brasil a dignidade da pessoa humana, em seu artigo 1 을 inciso IV, e, no artigo 4ํㅡ, inciso II, o princípio da prevalência dos direitos humanos no âmbito das relações institucionais internacionais, além de reservar um título específico para encartar o rol de direitos e garantias fundamentais individuais e coletivos.

Vale consignar, igualmente, que o compromisso de proteção dos direitos fundamentais está presente nos artigos XXI e XXIX, alínea 2, da Declaração Universal de Direitos Humanos, da qual a República Federativa do Brasil é signatária (COMPARATO 2003, p. 231).

Este modelo estatal tem como intenção basilar a mudança do status quo da sociedade. Nesse sentir, complementa Jean Carlos Dias (2007, p. 154) que "uma vez que a sociedade estrutura-se sob a forma de um Estado Democrático de Direito, a linha de condução política é a submissão a proteção aos direitos fundamentais".

Outrossim, o Estado Democrático de Direito surge para operacionalizar uma transformação da realidade social, rompendo com o modelo clássico de Estado Liberal, voltado para a defesa de direitos e garantias de 1a geração, a partir da implantação de uma progressiva igualdade material:

A democracia aqui não tem sentido simplesmente formal, como no Estado Liberal, mas precisamente substancial e se pauta pela efetivação dos direitos fundamentais e pela preservação da dignidade da pessoa humana. O Estado não mais pode conviver passivamente com as desigualdades e injustiças sociais. Ele tem que atuar para se reestruturar, reestruturando também a sociedade (ALMEIDA, 2003, p. 55).

A partir desta visão de um Estado social, os direitos fundamentais ganham nova amplitude, não se limitando apenas às liberdades individuais consagradas pelo Estado liberal. 
Nesta nova perspectiva, o texto constitucional consagrou direitos que impõem deveres positivos ou de prestação mediante a prática, pelo Estado, de atos necessários para que o bem da vida esteja à disposição do cidadão.

Com esta diretriz tão marcante, cabe aos poderes do Estado valerem-se dos instrumentos hábeis à efetiva materialização de uma ordem social mais justa, uma vez que pouco vale o mero reconhecimento formal de direitos se eles não são acompanhados de instrumentos para efetivá-los.

Esta noção deriva da premissa contida no conceito de força normativa da Constituição e aplicação imediata das normas constitucionais, de maneira que se torna possível falar em um direito constitucional à efetivação da Constituição:

Quaisquer que sejam os programas e projetos governamentais, ou eles se ajustam aos princípios e diretrizes constitucionais ou, inexoravelmente, haverão de ser tidos como inválidos, juridicamente insubsistentes e, portanto, sujeitos ao mesmo controle jurisdicional de constitucionalidade a que se submetem as leis. Como igualmente ponderado é observar que a abstinência do governo em tornar concretos, reais, os fins e objetivos inseridos em tais princípios e diretrizes constituirá, inelutavelmente, uma forma clara de ofensa à Constituição e, consequentemente, de violação de direitos subjetivos dos cidadãos (PONTES FILHO, 2003, p. 244).

E é sob este prisma que se apresentam indispensáveis as denominadas políticas públicas, que, de um modo geral, representam um conjunto ou uma medida isolada praticada pelo Estado com o desiderato de dar efetividade aos direitos fundamentais ou ao Estado Democrático de Direito (FREIRE JÚNIOR, 2005, p. 47).

Conforme bem destaca Eros Grau (2000, p. 21):

A expressão política pública designa a atuação do Estado, desde a pressuposição de uma bem demarcada separação entre Estado e Sociedade [...]. A expressão 'políticas públicas' designa todas as atuações do Estado, cobrindo todas as formas de intervenção do poder público na vida social.

Percebe-se que é possível atribuir ao Estado Social o desenvolvimento de políticas públicas voltadas a estender a todos os indivíduos os direitos fundamentais, incluindo os direitos sociais. 
Logo, as políticas públicas constituem os mecanismos de que dispõe o Estado para a concretização de direitos fundamentais, mediante a satisfação espontânea dos bens da vida por eles protegidos.

Partindo-se deste raciocínio, observa-se, neste modelo estatal, a importância de ser enfatizada a independência de um Poder Judiciário mais atuante, com a ampliação do mecanismo de controle sobre atuações estatais que eventualmente venham a se distanciar da aplicação das leis segundos os fins sociais:

É, portanto, no Estado Democrático de Direito que o Estado-jurisdição assume novo papel. Comprometido constitucionalmente com a problemática social, o Judiciário passa a ser Poder transformador da realidade social ao não poder criar obstáculos a realização de direitos fundamentais (ALMEIDA, 2003, p. 59).

Isto porque a Constituição Federal vincula todo o aparato estatal à efetivação de direitos fundamentais, eis que, uma vez institucionalizados, produzem efeito de irradiação por todo o ordenamento jurídico, atrelando a atuação de todas as formas de expressão do poder estatal:

Os atos legislativos, administrativos e judiciais, por conseguinte, devem ser produzidos em conformidade com o princípio da efetivação dos direitos fundamentais, mediante impulsos e diretivas de atuação com vistas a sua plena satisfação (CANELA JúNIOR, 2011, p. 41).

Percebe-se, por conseguinte, que os direitos fundamentais, por consubstanciarem bens da vida intimamente essenciais à existência humana digna, devem ser atendidos, respeitados e efetivados com absoluta preferência pelos poderes estatais, além de constituírem o pilar do sistema ético de referência de todo o ordenamento jurídico brasileiro.

Elucidando este preceito, acrescenta Osvaldo Canela Junior (2011, p. 44):

A prioridade é determinante na atuação de todas as formas de expressão do poder estatal. Os atos legislativos, administrativos e judiciais devem priorizar o exame e a concretização dos direitos fundamentais, cada qual dentro da sua órbita de atuação. Qualquer ato, comissivo ou omissivo, das formas de expressão estatal que não priorize a efetivação dos direitos fundamentais é inconstitucional. 
Preconizando expressões desta preocupação com a efetiva promoção dos direitos fundamentais via adoção de políticas públicas, a Constituição Federal, primou pela delineação de um Estado Social e passou a contemplar normas que pudessem viabilizar a implantação de programas para a consecução dos aludidos direitos.

Estas normas são as chamadas normas constitucionais programáticas, responsáveis por representar os dispositivos definidores dos fins sociais a serem alcançados pela sociedade e por estipular os princípios ou programas a serem cumpridos pelo Poder Público (TAVARES, 2007, p. 96).

Por meio das referidas normas, o constituinte traçou os princípios a serem observados pelos órgãos estatais (legislativos, executivos, jurisdicionais e administrativos), como os programas das respectivas atividades, com o fito de realização dos fins sociais do Estado. São exemplos claros de normas programáticas os artigos 205 (educação), 215 (cultura), 217 (desporto) e 227 (proteção da criança).

Este grupo de normas constitui o sentido hermenêutico de interpretação, integração e aplicação das normas jurídicas, condicionando, inclusive, a atividade discricionária da Administração Pública.

Portanto, neste contexto de Estado Democrático e Social de Direito cuja diretriz se baseia na promoção de direitos fundamentais e estabelece programas a serem seguidos pelo Estado a fim de efetivá-los, vale destacar o novo papel do Poder Judiciário.

Enquanto em um Estado liberal a tarefa prevista para o Poder Judiciário estava bem limitada a aplicar a lei ao caso concreto, evitando a interferência das demais formas de expressão do poder estatal na esfera de liberdade dos cidadãos, sob a égide de um Estado social o Poder Judiciário deve ampliar o sentido de alcance da lei, informado pelas normas descritivas de programas de atuação estatal (normas constitucionais de princípio programático), e trazer para o campo jurisdicional condutas historicamente atreladas à atuação exclusiva do legislador e administrador.

Conforme aventado, a inserção de normas programáticas no bojo do texto constitucional brasileiro convocou o Poder Judiciário a decidir a respeito da compatibilidade dos atos comissivos e omissivos das demais formas de expressão do poder estatal, o que 
envolve, em muitas das vezes, o exame dos critérios de escolha do administrador em cotejo com a finalidade do ato administrativo (CANELA JÚNIOR, 2011, p. 79-80).

Como se vê, há uma tendência indisfarçável de vinculação de todos os atos das mais variadas formas da expressão da vontade estatal às finalidades constitucionais atinentes à promoção de direitos fundamentais.

Torna-se lógico depreender que quaisquer condutas praticadas por agentes públicos, no exercício da função pública, que se distanciem dos objetivos consagrados pela lei e Constituição, estarão sujeitas ao controle de legalidade e constitucionalidade exercido pelo Poder Judiciário.

Como as condutas descritas na Constituição Federal tendentes à realização de direitos fundamentais se manifestam por meio de normas programáticas e são materializadas pelo Estado por meio de promoção de políticas públicas, há que se admitir que o Poder Judiciário possua fundamentos constitucionais bastantes para efetuar o controle jurisdicional referente a problemas oriundos das condutas dos agentes públicos no exercício de políticas públicas relacionadas à efetivação de direitos fundamentais.

Nesse diapasão, Aury Lopes Junior (2005, p. 73) afirma com propriedade que

A legitimidade democrática do juiz deriva do caráter democrático da própria Constituição, e não da vontade da maioria. O juiz tem uma nova posição dentro do Estado de Direito e a legitimidade de sua atuação não é política, mas constitucional, e seu fundamento é unicamente a intangibilidade dos direitos fundamentais. É uma legitimidade democrática, fundada na garantia dos direitos fundamentais e baseada na democracia substancial.

Ademais, não se trata, absolutamente, de tentativa de conceder um poder ilimitado aos juízes ao examinar as políticas públicas. Pelo contrário, o que se pretende é fortalecer o cumprimento do princípio da prevalência dos direitos humanos mediante a atuação de um Poder Judiciário que possa subordinar os demais poderes à autoridade da jurisdição constitucional.

Com esta linha de entendimento, destaquem-se as lições de Gustavo Binenbojm (BINEMBOJM, 2001, p. 54):

É louvável o esforço das teorias contemporâneas sobre democracia e direitos fundamentais no sentido de balizamento de um âmbito próprio de atuação da 
jurisdição constitucional, que a torne compatível com o sistema de separação e harmonia entre os poderes. Mais do que meros corretivos liberais do princípio majoritário, os direitos fundamentais se afirmam, hodiernamente, como condições estruturantes da própria democracia; devem eles, por isso, ficar à margem das disputas políticas, sob a proteção de um órgão independente e capaz de subordinar os demais poderes à autoridade moral e intelectual de suas decisões.

Desse modo, quando a atividade jurisdicional anula leis e atos ofensivos a princípios e direitos fundamentais constitucionalmente consagrados, sua intervenção se dá a favor da democracia, e não contra. Esta é, por conseguinte, a maior fonte de legitimidade da atuação jurisdicional para o controle de políticas públicas implementadoras de direitos fundamentais.

Indo além, merece ser destacado também o princípio da inafastabilidade da jurisdição, enunciado sinteticamente no artigo 50, inciso XXXV, da Constituição Federal de 1988, que estabelece que a lei não excluirá da apreciação do Poder Judiciário lesão ou ameaça a direito.

Uma interpretação adequada do dispositivo leva à conclusão de que não somente lei, mas também atos, inclusive omissivos, do Poder Legislativo e Executivo não podem ficar sem controle.

Segundo Osvaldo Canela Junior (2011, p. 136), em matéria de direitos fundamentais e políticas públicas, o postulado da inafastabilidade da jurisdição ganha um novo alcance interpretativo, dele decorrendo o princípio da proibição da resistência instrumental dos direitos fundamentais:

\footnotetext{
Segundo o princípio da proibição de resistência instrumental aos direitos fundamentais, nenhuma política pública, oriunda do Poder Legislativo ou do Poder Executivo, poderá se converter, comissiva ou omissivamente, em instrumento de resistência à efetivação dos direitos fundamentais. Logo, não somente os atos administrativos e de governo poderão ser examinados pelo Poder Judiciário sob este prima, como também as normas subconstitucionais, as quais constituem o produto de uma política pública mais ampla daqueles poderes.
}

Por outro lado, o princípio da inafastabilidade da jurisdição deve ser interpretado tendo como norte o sistema ético de referência adotado pela Constituição Federal de 1988 no que toca a direitos fundamentais, segundo o qual devem ser adotadas todas as condutas tendentes à satisfação destes direitos. 
Conclui-se, portanto, que, existindo direito subjetivo amparado, bem como a alegação de lesão a este direito, o Poder Judiciário está constitucionalmente vinculado a prestar jurisdição e permitir a discussão democrática sobre a violação de direitos fundamentais decorrentes de prestação insuficiente ou omissa de políticas públicas pelo Estado.

Frise-se, ainda, que em nenhum momento deve ser colocado o Poder Judiciário acima dos demais poderes em matérias de políticas públicas. Ao revés, ordinariamente compete ao Executivo e Legislativo efetivarem a Constituição. Somente quando tal dever for descumprido por desvios de finalidades legais e constitucionais ou de forma arbitrária, o Poder Judiciário deve intervir.

A esse respeito, discorre Osvaldo Luiz Palu (2004, p. 82):

No Estado Democrático de Direito, a questão da escolha de prioridades cabe a um legislador democraticamente eleito e, em nosso sistema presidencialista, a um governo democraticamente eleito, que, como sabemos, trata-se do Executivo e sua base de apoio parlamentar. E somente em casos de desvios erráticos ou de uma passividade arbitrária ante casos evidentes de situações precárias cabe uma correção, constitucionalmente fundada em atos de governo.

Por fim, cabe frisar que não existe discricionariedade na omissão do cumprimento da Constituição. Na verdade, trata-se de arbitrariedade que pode e deve ser corrigida.

\section{Controle judicial de políticas públicas e o princípio da separação dos poderes}

O princípio da separação dos poderes resta positivado no artigo 20 da Constituição Federal, ao prever que são Poderes da União, independentes e harmônicos entre si, o Legislativo, o Executivo e o Judiciário.

Destaque-se, de plano, que a nomenclatura separação de poderes não deve prosperar, uma vez que, efetivamente, o poder estatal é uno, deriva da soberania popular e está inteiramente subordinado à obediência das normas constitucionais. O que existe, em verdade, é separação das funções de legislar, administrar e julgar, visando dar a máxima efetividade possível à Constituição (FREIRE JÚNIOR, 2005, p. 37). 
Em cotejo com o tópico anterior, é essencial analisar a interpretação de funcionamento deste princípio no âmbito do Estado Democrático e Social de Direito proposto pela Constituição Federal vigente.

Para que seja mais bem compreendida esta questão, merece ser brevemente abordada a origem deste princípio no contexto do Estado liberal, a fim de que reste clara a evolução da sua interpretação no contexto do Estado Democrático e Social de Direito.

O nascimento da concepção da separação de poderes remete ao século XVII, auge do movimento iluminista e dos ideais libertários propagados pela burguesia europeia contra as monarquias absolutistas.

Nesse estado de coisas, a teoria da separação dos poderes foi concebida por Montesquieu para assegurar a existência de um governo moderado, mediante controle recíproco entre as formas de expressão da vontade estatal. O famoso teórico político objetivava propor uma teoria para evitar a concentração de poderes de tal forma que os direitos e liberdades fundamentais fossem protegidos das investidas do poder arbitrário do rei (MONTESQUIEU, 2008).

Vislumbra-se que, em sua origem, este princípio se voltava precipuamente à proteção das liberdades fundamentais individuais de primeira geração, mediante o controle entre poderes a fim de desconcentrar todas as funções estatais então centralizadas na figura monárquica:

\footnotetext{
A restrição do poder dos órgãos do Estado era indispensável, em uma fase histórica na qual o despotismo pregava o poder absoluto e arbitrário. Foi, portanto, a primeira reação ao arbítrio, consignada nos textos constitucionais, com o específico fim de adequar o perfil das forças de expressão do poder estatal (CANELA JÚNIOR, 2011, p. 70).
}

Nota-se que este modelo de constitucionalismo liberal preocupava-se, com exclusividade, em proteger o indivíduo da ingerência estatal, sem impor qualquer orientação finalística em termos de ação governamental. Isto ocorreu porque, até determinado momento da história, a proteção dos direitos fundamentais de primeira geração era o principal alvo sobre o qual se debruçava a teoria política.

Entretanto, a partir do fenômeno histórico da revolução industrial, a expansão da produção e consumo de massas, bem como a integração global da informação, houve a 
transição para um paradigma de Estado Social, acompanhada de uma substancial mudança na concepção de Estado e sua finalidade.

Segundo Paulo Bonavides (1980, p. 43), "o dirigismo estatal, característica do Estado social, implica o estabelecimento de funções específicas aos poderes públicos para a consecução de metas predeterminadas pela coletividade."

Consagrou-se o juízo segundo o qual os direitos de primeira geração seriam efetivamente protegidos caso assegurados, conjuntamente e mediante ações afirmativas, outros bens jurídicos essenciais relacionados a coletividade como um todo, tais como a saúde, educação, trabalho, habitação, família, entre outros. (CANELA JÚNIOR, 2011, p.71)

Nesta linha de entendimento, Fabio Konder Comparato (1986, p. 11-12) explicita como essa mudança na maneira de enxergar o papel do Estado influenciou o modo com que foi concebido o princípio da separação dos poderes:

\footnotetext{
Sem dúvida alguma, a estabilidade objetivada no Estado liberal é substituída pelo dirigismo estatal, alterando-se, de forma profunda, a concepção da teoria da separação dos poderes. Aquele modelo rígido de separação de poderes, baseado na independência, ausência de rivalidades, sem entrechoques, sem conflitos, restou abolido das modernas constituições de quase todos os países.
}

Constata-se, portanto, uma nova conformação do Estado e, via de consequência, da própria teoria da separação dos poderes.

Enquanto no Estado liberal o objeto da tripartição de poderes seria evitar a concentração do poder estatal em estrito respeito às liberdades individuais, no Estado social esta ideia permanece, mas a ela é acrescentado o desiderato da concretização dos direitos fundamentais de segunda e demais gerações.

Com efeito, demanda-se do Estado não somente uma postura meramente negativa perante o indivíduo, mas também uma conduta proativa com o propósito de assegurar a igualdade substancial entre os cidadãos.

Complementando esta noção, arremata Americo Bedê Freire Junior (2005, p. 38):

Deve ser frisado que não apenas os direitos da primeira geração devem ser protegidos pela separação dos poderes, mas todas as gerações dos direitos fundamentais, já que uma das características dos direitos fundamentais é a sua indivisibilidade. Todas as dimensões dos direitos fundamentais, portanto, podem (devem) ser protegidas pelo princípio em comento. 
Nota-se, assim, a amplificação da função judicial, que no modelo de tripartição dos poderes do Estado liberal restringia sua atuação à solução de conflitos individuais, já que o espaço público deveria ser ocupado apenas pelos eleitos pela população.

Com o estabelecimento de um Estado Democrático e Social de Direito e a positivação de normas constitucionais programáticas determinando planos de governo voltados especialmente para os direitos de segunda geração, o Judiciário passa a intervir mais ativamente no espaço público:

\begin{abstract}
Contudo, pode-se afirmar que, se o princípio da separação dos poderes foi inicialmente idealizado com a finalidade de conter o arbítrio estatal, atualmente, a remissão a ele de modo a justificar a impossibilidade do controle jurisdicional sobre as políticas públicas visa garantir a manutenção do status quo, dando um caráter de pretensa "juridicidade" à omissão do Estado quanto aos seus deveres de realizar os direitos fundamentais, por meio das políticas públicas. Nesse sentido, entendese competir ao Poder Judiciário, à luz do princípio da separação dos poderes, a tarefa de tutelar a Constituição, de modo que os preceitos nela contemplados tenham efetividade, não podendo, portanto, encontrar guarida na doutrina da separação dos poderes, a omissão estatal desarrazoada no cumprimento desse dever (ARAUJO, 2006, p. 118).
\end{abstract}

Dentro desta nova proposta de atuação do Poder Judiciário na teoria da separação dos poderes no Estado social, Lenio Streck (1988, p. 323) aponta que, a partir da nova ordem jurídica instaurada a partir da Constituição Federal de 1988,

as inércias do Executivo e falta de atuação do legislativo passam a poder ser supridas pelo Judiciário, justamente mediante a utilização dos mecanismos previstos na Constituição que estabeleceu o Estado Democrático de Direito.

Sob outro giro, Andreas Krell (2000, p. 29) pontifica que

Parece-nos cada vez mais necessária a revisão do vetusto dogma da separação dos poderes em relação ao controle dos gastos públicos e da prestação dos serviços sociais básicos no Estado Social, visto que os Poderes Legislativo e Executivo no Brasil se mostram incapazes de garantir um cumprimento racional dos respectivos preceitos constitucionais.

Nessa toada, pode-se extrair uma preocupação comum de que haja um novo perfil de atuação do Poder Judiciário, mais alinhado com a afirmação dos direitos fundamentais na Constituição do Estado Democrático e Social de Direito. 
Constata-se, por conseguinte, o paradoxo de se apontar a separação dos poderes como entrave ao controle judicial de políticas públicas, uma vez que tal interpretação aniquila a premissa de que este princípio deve servir de meio para dar efetividade ao texto constitucional.

Ora, a divisão de poderes não pode significar a privação dos poderes públicos das competências necessárias para o cumprimento de suas tarefas constitucionais.

Cumpre salientar que é da própria natureza do Poder Judiciário interferir sobre o exercício da atividade dos demais poderes, na medida em que é o poder constitucionalmente responsável pela função de verificar a compatibilidade destas atividades com a Constituição Federal (APPIO, 2005, p. 149-150).

Neste aspecto, a atuação jurisdicional reflete a atividade corretiva do Estado-juiz, com o propósito de atender aos objetivos constitucionais por meio da satisfação dos direitos fundamentais.

Ao prolatar uma sentença na qual vincula o agente público à satisfação do bem da vida tutelado pelo direito fundamental, o Poder Judiciário não está interferindo arbitrariamente na escolha dos caminhos hábeis à consecução material do direito fundamental, mas presta única e exclusivamente atividade jurisdicional, residual e integradora, dando completude ao ordenamento jurídico-constitucional.

E assim o faz em plena harmonia, porquanto tão somente redireciona as políticas públicas, no limite do necessário para a consecução do princípio da igualdade substancial.

Conclui-se, em arremate, que a noção de Estado Democrático e Social de Direito estatuída pela Constituição Federal de 1988 é incompatível com uma visão de separação de poderes que inviabilize o amplo controle de constitucionalidade visando à efetivação dos direitos fundamentais.

\section{Políticas públicas e a reserva do possível}

Um dos argumentos frequentemente adotados por aqueles que se posicionam contrariamente ao controle judicial de políticas públicas é o da denominada reserva do possível. 
A expressão traduz a ideia de limitação dos recursos orçamentários disponíveis para fazer frente a uma ilimitada e dispendiosa demanda social a ser por eles suprida.

Segundo este entendimento, esta restrição financeira justificaria, em certos casos, a não efetivação dos direitos previstos em lei por parte do Estado:

A expressão reserva do possível procura identificar o fenômeno econômico de limitação dos recursos disponíveis diante das necessidades quase sempre infinitas a serem por eles supridas. [...] A reserva do possível significa que, para além das discussões jurídicas sobre o que se pode exigir judicialmente do Estado - e em última análise da sociedade, já que é esta que o sustenta -, é importante lembrar que há um limite de possibilidades materiais para estes direitos (BARCELLOS, 2002, p. 236).

O debate, neste caso, vai além do campo jurídico e adentra no contexto fático, na medida em que perquire acerca da possibilidade material do Estado de atender em sua plenitude todas as necessidades da população, em contraposição a um orçamento que nem sempre oferecerá totais condições de satisfação das demandas coletivas.

No que concerne ao aspecto jurídico da reserva do possível, argumenta-se a necessidade de prévia dotação orçamentária como limite ao cumprimento imediato da decisão judicial que determina a implementação de uma política pública.

De fato, para concretizar os programas estatais estipulados como deveres para efetivar direitos e políticas previstos constitucionalmente, a Administração Pública faz uso de ações positivas, prestações materiais que necessitam de recursos orçamentários para serem concretizadas.

Nesta linha de pensamento, não poderia o Judiciário simplesmente ignorar esta limitação financeira no momento de determinar que o Administrador público adote certa medida.

De plano, cabe ressaltar que esta alegação de insuficiência de fundos não pode ser genérica, devendo ser detalhadamente demonstrada pelo ente público.

Discorrendo sobre o tema, George Marmelstein Lima (2004, p. 57) aduz que

Há que ser feita, contudo, uma advertência: as alegações de negativa de efetivação de um direito social com base no argumento da reserva do possível devem ser sempre analisadas com desconfiança. Não basta simplesmente alegar que não há possibilidades financeiras de se cumprir a ordem judicial; é preciso demonstrá-la. $O$ 
que não se pode é deixar que a evocação da reserva do possível converta-se em verdadeira razão de Estado econômica, num Al-5 econômico que opera, na verdade, como uma anti-Constituição, contra tudo o que a Carta consagra em matéria de direitos sociais.

Assim, antes de ser acolhida superficialmente a justificação de falta ou escassez de recursos, é preciso averiguar seus motivos e se, efetivamente, ela existe.

Sob outro vértice, é preciso sublinhar que, se os recursos não são suficientes para cumprir integralmente a política pública, não significa que sejam insuficientes para, ao menos, iniciá-la.

Deste modo, nada impede que se comece a materialização dos direitos fundamentais e, posteriormente, seja analisado como podem ser introduzidos novos recursos para dar seu prosseguimento.

O que não parece razoável é simplesmente o Poder Executivo ou Legislativo descumprir a Constituição e a decisão judicial, sob o singelo argumento de que não possui recursos para tal (FREIRE JÚNIOR, 2005, p. 74).

Conforme aventado ao longo deste trabalho, todas as formas de expressão da vontade estatal encontram-se constitucionalmente vinculadas ao compromisso de efetivação de direitos fundamentais, de modo que a mera e simples alegação de falta de recursos deve ser analisada cautelosamente quando arguida, devendo prevalecer a postura de diálogo entre as funções estatais em prol do respeito aos direitos fundamentais.

Indo além, se a Constituição prevê que a lei não excluirá de apreciação lesão ou ameaça de lesão a direito (inafastabilidade da jurisdição), não poderá o Poder Judiciário afastar a tutela jurisdicional pleiteada por fundamentos externos ao Direito, sob a invocação de um fator econômico:

Constata-se que o fenômeno econômico tem sido invocado para impedir a concessão de direitos fundamentais sociais pelo Poder Judiciário. Alega-se, em geral, que o Poder Judiciário não pode conceder direitos cuja satisfação demandará receitas não disponíveis pelo Estado. Tal fundamento, contudo, traz em si a desconsideração de que o Estado brasileiro possui objetivos a serem efetivamente atendidos, de tal forma que o orçamento há de servir como instrumento para a respectiva realização, e não como óbice (CANELA JÚNIOR, 2011, p. 102). 
Insta asseverar que o Poder Judiciário encontra-se vinculado aos objetivos preconizados no artigo 3ำ da Constituição Federal, e não com programas partidários ou conveniências de agentes públicos e injunções de ordem orçamentária.

Assim, comprovada a lesão a direito fundamental a ser suprida mediante a execução de políticas públicas, deverá o juiz exarar sentença de mérito a respeito da matéria.

Todavia, se nas circunstâncias fáticas o poder público não possuir recursos financeiros bastantes para execução da decisão, esta sentença servirá para determinar a inclusão de dotação orçamentária específica para o exercício financeiro seguinte. Trata-se de posicionamento que melhor se coaduna com o princípio da dignidade da pessoa humana e da máxima efetividade dos direitos fundamentais.

Merece destaque, neste ponto, citar o artigo 2 - -1 , do Pacto Internacional dos Direitos Econômicos, Sociais e Culturais, do qual o Brasil é signatário, segundo o qual cada Estado-parte compromete-se a adotar medidas, principalmente no plano econômico e técnico, até o máximo de seus recursos disponíveis, a fim de assegurar, progressivamente, o pleno exercício dos direitos reconhecidos, incluindo, em particular, as medidas legislativas.

Não se pretende, com este posicionamento, menosprezar a importância das regras orçamentárias e do direito financeiro, mas é preciso analisar detalhadamente a escassez de recursos em cada concreto, com o propósito de apurar até que ponto empecilhos formais e econômicos podem afastar a materialização da essência da Constituição.

As políticas públicas não estão mais a mercê da ilimitada discricionariedade do Administrador público. Se, por um lado, o agente público dispõe de margem de discricionariedade para decidir que medida irá tomar, no caso concreto, segundo seus critérios de conveniência e oportunidade (denominado mérito do ato administrativo), por outro lado ele está estritamente vinculado ao dever de alcance da finalidade legal e constitucional.

Logo, a discricionariedade de eleição das condutas a serem praticadas não é ilimitada.

Nesse sentido, colhem-se a lições de Celso Antônio Bandeira de Mello (2008, p. 1516): 


\begin{abstract}
Sabe-se que a ideia corrente da discricionariedade, entretanto, enfatiza a noção de poder. Enfatiza, de conseguinte, a presunção de que o agente público, quando a lei Ihe outorga aquilo que se denomina discricionariedade, dispõe de um poder para fazer escolhas livres, na suposição de que dentre as alternativas comportadas pela norma em abstrato, quaisquer delas são de indiferente aplicação no caso concreto. É esta ideia que normalmente se tem de discricionariedade. Pretende-se, justamente, demonstrar que não é assim que é preciso refazer a noção mais corrente de discricionariedade, para adequá-la ao próprio direito positivo.
\end{abstract}

Mais a frente, retomando a premissa de que a finalidade da lei delimita o campo de discricionariedade do poder público, o ilustre doutrinador acrescenta:

\begin{abstract}
Estabelecido que a lei sempre e sempre impõe, como é natural, o dever de buscarse a medida que atenda de modo preciso sua finalidade, resulta certo que a liberdade administrativa acaso conferida por uma norma de direito não significa sempre liberdade de eleição entre indiferentes jurídicos. Não significa poder de opções livres, como as de direito privado. Significa o dever jurídico funcional (questão de legitimidade e não de mérito) de acertar, ante a configuração do caso concreto, a providência ideal, capaz de atingir com exatidão a finalidade da lei, dando, assim, satisfação ao interesse coletivo (BANDEIRA DE MELLO, 2008, p. 47).
\end{abstract}

Este mencionado dever jurídico funcional de acertar a providência ideal capaz de atingir com exatidão a finalidade legal está em perfeita sintonia com o modelo de Estado de Direito consagrado pela Constitucional Federal de 1988.

Em decorrência disto, toda vez que o administrador público se afastar, no exercício do poder discricionário, do cumprimento da finalidade legal, estará incorrendo no chamado desvio de poder, ilegalidade traduzida pelo comportamento do agente público que atua em desacordo com a finalidade que melhor atende o interesse público, expressada no comando legal.

Nesta hipótese, o agente público haverá ultrapassado o campo de liberdade que the assistia (mérito do ato), ou seja, terá transgredido a sua esfera discricionária para invadir setor proibido.

O ato será ilegítimo e, consequentemente, o Poder Judiciário poderá fulminá-lo por ser conduta ofensiva ao direito e que de modo algum poderá remanescer válida.

Esta lição é valiosa para justificar a possibilidade de controle judicial de políticas públicas nos casos em que a limitação orçamentária exige a escolha de prioridades de atendimento por parte do administrador público. 
Esta eleição, como não poderia deixar de ser, deve ser tomada tendo como norte o referencial ético dos princípios constitucionais e da ideia de máxima efetivação dos direitos fundamentais.

Não parece legítimo, por exemplo, alegar insuficiência de recursos para realização de investimentos na área de saúde quando existem, no mesmo orçamento, abundantes recursos destinados à propaganda governamental.

Neste caso, os finitos recursos do Estado devem orientar uma conduta do administrador público no sentido de prestigiar as áreas relacionadas aos direitos fundamentais, que gozam de tutela prioritária no bojo do texto constitucional.

Com efeito, se no caso concreto o Poder Executivo afastou-se, no exercício de sua competência discricionária, do cumprimento da finalidade legal e constitucional, incorrendo em desvio de poder, o ato poderá perfeitamente ser controlado e, sendo o caso, declarado nulo pelo Poder Judiciário.

Ao final, nota-se que a reserva do possível é um argumento que deve ser sopesado segundo as circunstâncias peculiares do caso concreto submetido à apreciação jurisdicional, sem perder de vista conceitos importantes como mérito do ato administrativo discricionário, seus limites e possibilidades do mesmo ser sindicado pelo Poder Judiciário em caso de não atendimento do interesse público, violação dos princípios constitucionais e direitos fundamentais.

\section{Conclusão}

Buscou-se pelo presente estudo tecer considerações acerca da possibilidade de controle de políticas públicas relacionadas a direitos fundamentais pelo Poder Judiciário, com consequente intervenção nos atos praticados pelas demais formas de manifestação do poder estatal.

A discussão deve tomar como pano de fundo o modelo de Estado Democrático e Social de Direito consagrado pela Constituição Federal de 1988.

Este paradigma estatal estatui como pilar do ordenamento jurídico o princípio da dignidade da pessoa humana e da máxima efetivação dos direitos fundamentais, de modo 
que todas as funções estatais encontram-se constitucionalmente vinculadas à consecução destes preceitos.

Com a proposta de complementar o modelo de Estado liberal, limitado à tutela das liberdades individuais perante o arbítrio estatal, o texto constitucional consagrou por meio de normas programáticas os direitos fundamentais de segunda geração, os quais impõem ao Estado os deveres positivos de prestação material para que o bem da vida esteja à disposição do cidadão, tais como o direito à educação, saúde e saneamento básico.

Neste modelo, as políticas públicas constituem elementos capitais, na medida em que são os mecanismos de que dispõem o Estado para a concretização dos direitos fundamentais.

Logo, o Poder Judiciário, como qualquer outra forma de expressão do poder estatal, tem o dever constitucional e o compromisso ético de apreciar as demandas que envolvam lesão a quaisquer direitos fundamentais em razão de ausência ou insuficiência na promoção de políticas públicas.

A inserção de normas programáticas relacionadas aos direitos sociais convocou o Poder Judiciário a decidir a respeito de questões historicamente atreladas à atuação exclusiva do legislador e administrador, nos casos em que estes, por atos comissivos ou omissivos na implementação de políticas públicas, derem causa à lesão de direitos fundamentais.

Percebeu-se, ademais, que a transição do Estado liberal para o Estado social importou uma profunda alteração da concepção da teoria da separação dos poderes.

O Estado passa a assumir compromissos de realização social e vincula as formas de expressão de seu poder à consecução de seus fins. Assim, não se pode invocar a separação de poderes para justificar a ausência de atuação jurisdicional em casos de inércia do Executivo e Legislativo, pois significaria negar a premissa constitucional segunda a qual todos os poderes estatais possuem o dever de efetivar normas constitucionais, notadamente aquelas referentes a direitos fundamentais.

No que concerne à denominada reserva do possível, asseverou-se que a falta ou escassez de recursos para a adoção de políticas públicas deve ser devidamente comprovada 
e sopesada segundo as circunstâncias do caso concreto, buscando prevalecer o diálogo entre as funções estatais em prol do respeito aos direitos fundamentais.

Caso haja sentença de mérito determinando a reparação do direito lesado e o Estado não possua recursos orçamentários bastantes naquele momento, servirá o comando judicial para ordenar a alocação de dotação financeira específica para o orçamento do ano seguinte.

Por fim, viu-se que a discricionariedade do Administrador público quanto à adoção de políticas públicas não é mais vista de forma ilimitada, haja vista que a medida a ser tomada deve ser aquela que melhor atenda a finalidade constitucional de promoção dos direitos fundamentais.

Se, diante das circunstâncias do caso concreto, o agente público, no exercício do poder discricionário, distanciar-se do cumprimento da finalidade constitucional ao não implementar a contento as políticas públicas e gerar lesão a direito fundamental, o ato será ilegítimo e, portanto, passível de ser controlado pelo Poder Judiciário, com fundamento nos princípios constitucionais violados.

É importante ressalvar que não se pretende conceder um poder ilimitado aos juízes ao examinar a execução de políticas públicas, as quais são de competência originária dos agentes públicos eleitos pelo povo.

O que se buscou fundamentar foi a importância da atuação do Poder Judiciário quando o comportamento dos agentes públicos competentes se revestir de um grave desvio de finalidade ou uma inaceitável passividade diante do comando constitucional de concretização dos direitos fundamentais.

Em hipóteses tais, admitir o controle pelo Poder Judiciário em matéria de políticas públicas é a solução que melhor harmoniza-se com os critérios de justiça, proporcionalidade e razoabilidade que informam o ordenamento jurídico pátrio.

\section{Referências}

ALMEIDA, Gregório Assagra de. Direito processual coletivo brasileiro: um novo ramo do direito processual. São Paulo: Saraiva, 2003.

APPIO, Eduardo. Controle Judicial das Políticas Públicas no Brasil. Juruá: São Paulo, 2005. 
ARAUJO, Luiz Roberto David. Curso de Direito Constitucional. São Paulo: Saraiva, 2005.

ARAUJO, Ana Luiza Gomes de. Controle Jurisdicional de Políticas Públicas. Belo Horizonte. UFMG, 2006.

BANDEIRA DE MELLO, Celso Antônio. Discricionariedade e Controle Jurisdicional. Malheiros: São Paulo, 2008.

BARCELLOS, Ana Paula. A eficácia jurídica dos princípios constitucionais. Rio de Janeiro: Renovar, 2002.

BINENBOJM, Gustavo. A nova jurisdição constitucional brasileira. Rio de Janeiro: Renovar, 2001.

BONAVIDES, Paulo. Do Estado liberal ao Estado social. Rio de Janeiro: Forense, 1980.

BRASIL. Constituição da República Federativa do Brasil. Disponível em: <http://www.pl analto.gov.br/ccivil_03/Constituiçao/constitui\%C3\%A7ao.htm> Acesso em: 12 fev. 2012.

BRASIL. Decreto 591 de 6 de julho de 1992. Disponível em:

http://www.planalto.gov.br/ccivil_03/decreto/1990-1994/D0591.htm. Acesso em: 02 de abril de 2012.

CANELA JUNIOR, Osvaldo. Controle Judicial de Políticas Públicas. São Paulo: Saraiva, 2011.

COMPARATO, Fabio Konder. A afirmação histórica dos direitos humanos. São Paulo: Saraiva, 2003.

COMPARATO, Fabio Konder. Ensaio sobre juízo de constitucionalidade de políticas públicas. RT: São Paulo, ano 86, n. 737, p. 11-22.

DIAS, Jean Carlos. O controle judicial de políticas públicas. São Paulo: Método, 2007.

DRUMMOND, Letícia Barbosa Drummond. Controle Judicial das Políticas Públicas e o Princípio da Reserva do Possível. Disponível em:

<http://www.fmd.pucminas.br/Virtuajus/1_2008/Discentes/Controle\%20Judicial.pdf>. Acesso em: 4 abr. 2012.

FREIRE JUNIOR, Américo Bedê. O controle judicial de políticas públicas. São Paulo: Editora Revista dos Tribunais, 2005.

GRAU, Eros Roberto. O Direito posto e o direito pressuposto. São Paulo: Malheiros, 2000. 
KRELL, Andreas. Controle judicial dos serviços públicos básicos na base dos direitos fundamentais sociais: a Constituição concretizada construindo pontes com o público e $o$ privado. Porto Alegre: Livraria do Advogado, 2000.

LIMA, George Marmelstein. Crítica à teoria de gerações (ou mesmo dimensões) dos direitos fundamentais. Caxias do Sul: Plenum, 2004.

LOPES JUNIOR, Aury. Introdução crítica ao processo penal. Rio de Janeiro: Lumen Juris, 2005.

MONTESQUIEU. O espírito das leis. São Paulo, Saraiva: 2008, livro XI, capítulo VI.

PALU, Osvaldo Luiz. Controle dos atos de governo pela jurisdição. São Paulo: RT, 2004.

PONTES FILHO, Valmir. O controle das políticas públicas. São Paulo: Malheiros, 2003.

STRECK, Lenio. As constituições sociais e a dignidade da pessoa humana como princípio fundamental. Rio de Janeiro: Renovar, 1988.

TAVARES, André Ramos. Curso de Direito Constitucional. São Paulo: Saraiva, 2007.

Artigo recebido em 02/07/2012 e aprovado para publicação em 30/11/2012. 
